active in the mouse. On the other hand, 'Mepacrine', which was active against equine encephalomvelitis virus in the mouse and adolescent rat, was inactive against this virus in the chicken, guinea pig, rabbit and monkey.

Work on simple antimetabolites, in which the furan ring had been substituted for the ribofuranoside moiety in the nucleoside, had led eventually to certain tetrahydropyrimidines which showed activity against viruses of the psittacosis-lymphogranulomatrachoma group both in the chick embryo and in the mouse. One, 17,025 [5-methoxycarbonyl-6-methyl4 - (5 - nitrofuryl)-2 -oxo-1,2,3,4-tetrahydropyrimidine] which was sparingly soluble in water, had very low toxicity and was both effective and non-irritant when given by the intramuscular route. It showed, weight for weight, rather less than one-tenth of the activity of chlorotetracycline. Its elinical use might be envisaged (for example, against trachoma) when it was desirable to control an infection by infrequent parenteral therapy rather than by prolonged topical application or by frequent oral dosing.

The third paper, by Drs. D. J. Bauer and P. W. Sadler (Wellcome Laboratories), was concerned with the antiviral action of derivatives of isatin $\beta$-thiosemicarbazone on viruses of the pox group. These compounds are known to show antituberculous activity and they were later shown by American workers to have some antiviral action against vaccinia virus. However, the latter work was not followed up until the group at the Wellcome Laboratories commenced detailed investigations of a number of derivatives of isatin $\beta$-thiosemicarbazone on a number of different members of the pox virus group. Perhaps the most striking finding has been the selectivity of action of these compounds. Thus, isatin $\beta$-thiosemicarbazone and some of its derivatives are very active against vaccinia but have no activity against ectromelia virus; conversely, isatin $\beta-4^{\prime}: 4^{\prime}$-dialkylthiosemicarbazone and related compounds are highly active against ectromelia but not at all active against vaccinia virus. This specificity should provide an important clue to the mode of action of these compounds. To the authors it suggested that these compounds were not acting on some cellular enzyme required for viral synthesis, but that they were acting directly on the virus itself.

A most interesting aspect of this work is the finding that $N$-ethylisatin $\beta$-thiosemicarbazone, in doses of 0.03 and $0.015 \mathrm{mgm}$. twice daily for five days, protected infant mice (less than six days old) against fatal infection by the viruses of alastrim and variola major. Dr. Bauer discussed at some length the question of the importance of the treatment of smallpox in these days of vaccination and he concluded that there was a strong case for trying out these compounds in man and that it was reasonable to expect that a specific anti-smallpox drug would be in use within the not too distant future.

Alick Isaacs

\title{
PHOSPHOLIPIDS AND SULPHOLIPIDS
}

$\mathrm{D}^{\mathrm{R}}$ R. M. MACFARLANE, joint chairman with Prof. D. D. Eley of the joint meeting of the Biochemical Society and the British Biophysical Society on "Phospholipids and Sulpholipids", which was held at the School of Pharmacy, University of London, during October 5-6, underlined its significance by a quotation from the Macleans (1927)" "When we consider the obscurity in which the chemistry of the phospholipids has been shrouded, it is easy to understand that many of the properties and functions ascribed to these bodies are based on little more than imagination." Thirty years later imagination remains in plenty, but an immense amount of accumulated factual evidence was presented at the meeting. The chemical, physical and physico-chemical problems surrounding phospholipids challenge all scientists interested in the structure and functions of the living cell.

With the advent of recent analytical procedures involving chemical ${ }^{2,3}$ or enzymatic hydrolysis, paper and silicic-acid chromatography ${ }^{4}$, the compositional detail of many animal and plant tissues is progressing fast. Consequently, the phospholipid ehemist of to-day recognizes phosphatidylglycerols ; phosphoinositides; the classical ester phosphatides having either serine, ethanolamine or choline as the nitrogenous base; the plasmalogens, being analogous to the phosphatides, but with an aldehyde in place of a fatty acid; the sphingomyelins, the complex phosphoinositols and finally the lysophosphatides. Among many most recent compositional details reported at the meeting was the observation by Dr. G. R. Webster that the ethanolamine base in brain white matter is predominantly present in plasmalogen instead of the more usual phosphatidyl ethanolamine. Dr. E. Lederer, withdrawing earlier claims, pointed out that mycobacteria do not appear to contain any nitrogenous base phospholipids but do yield mixtures of phosphatidyl-inosito-mono, di- and tri-mannosides. Of great interest, however, was his report on the structure of the phosphatidyl-inosito-dimannoside, and of his proof that the 6-O- $\alpha$-D-mannopyranosyl- $\alpha$ D-mannopyranose is inositol linked, the dimannosides alone being almost as effective as $B C G$ vacine in the protection of animals against tuberculosis.

In plant chloroplasts the major anionic lipids are phosphatidylglycerol and the sulpholipid, 6 -sulpho- $\alpha$ D-quinovopyranosyl-(1 $\left.\rightarrow 1^{\prime}\right)-2^{\prime}: 3^{\prime}$ diacyl glycerol. The precise formulation of the latter compound has been established by Dr. A. A. Benson in an elegant analytical procedure. The presence of lipid lamellæ in plant chloroplasts and the high-rate of incorporation of carbon-14 dioxide, phosphorus-32 labelled phosphate and sulphur-35 labelled sulphate ions into the anionic lipids during photosynthesis points to at least two functions of phospholipids--namely, interfacial orientation with concomitant orientation of adjacent molecules, such as enzymes, and involvement in translocation of metabolic products.

With commercially available gas chromatography apparatus, each phosphatide can now be examined in terms of its fatty acid composition. This further stage in the dissection of phospholipids was reported on by Dr. G. M. Gray, who compared the mean fatty acid composition of normal tissue phospholipids with those from Landschutz ascites tumour cells. Surprisingly, and perhaps of fundamental importance, the tumour cell phospholipids showed far less variation in the kind of fatty acid acylated. For example, stearic is the predominating saturated acid in all tumour phospholipids, thus differing from normal 
tissues in which palmitic acid is the major saturated acid of phosphatidyl choline and choline plasmalogen.

Prof. L. L. M. van Deenan and his colleagues at Utrecht rightly argued that a better understanding of the physical properties to be attributed to the fatty acids and to their particular position in the phosphatide molecule would clarify the biophysical properties of the phospholipid. Reporting a remarkable programme of syntheses involving re-acylation of $L-\alpha$ glyceryl phosphoryl choline, with fatty acids of varying chain-length, Prof. van Deenan was able to contribute experimental results obtained from his semi-synthetic material and relate it to many of the chemical and biophysical aspects covered during the meeting. Perhaps the most significant advance so far resulting from the use of these re-acylated phosphatides has been to establish beyond doubt that the phospholipases $A$ of snake or bee venoms only release the fatty acid from the $\beta$ position.

Combining biochemical and biophysical techniques, Dr. A. D. Bangham and Dr. R. M. C. Dawson presented substantial evidence to suggest that the activation of at least two phospholipases is controlled by the electrokinetic properties of the lipid/water interface. The $\zeta$ potential of lecithin suspensions was varied either by adding insoluble amphipathic molecules, for example, docosanyl pyridinium bromide or dicetyl phosphoric acid to the lecithin or by the addition of multivalent ions, for example, calcium ions or ferricyanide ions, to the bulk aqueous phase. Such experiments showed that Penicillium notatum phospholipase requires micelles having a net negative $(>15 \mathrm{mV}$.) $\zeta$ potential before hydrolysis of the lecithin occurred. Calcium, uranyl and thorium ions, if present, as multivalent gegen ions, inhibited the system. The phospholipase $C$ ( $\alpha$ toxin) of Clostridium perfringens, however, required a positively charged lipid interface and required either the addition of amphipathic cations to the lecithin, or divalent calcium or magnesium ions to the bulk aqueous phase. That these interactions are confined to the lipid-water interface was demonstrated by following the hydrolysis of unimolecular films using lecithin highly labelled with phosphorus-32. The ability of phospholipase $C$ ( $\alpha$ toxin) to hydrolyse phosphatidyl ethanolamine, but only in the presence of lecithin, confirms earlier work and fits in well with the hypothesis that lecithin, being a surface-active zwitterion, can dilute the high net negative charge of a pure phosphatidyl ethanolamine micelle with ionically neutral molecules, thereby permitting the negatively charged enzyme to approach the micelle. The adjustment of the net charge of lipids by admixture of lecithin may well be an important feature in a variety of biological systems, for example, blood coagulation, fat absorption. Endorsing the importance of a definitive lipid/water interface for the activation of phospholipase $C$, van Deenan reported that synthetic phosphatidyl cholines prepared with $\mathrm{C}_{2}$ or $\mathrm{C}_{4}$ fatty acids were not hydrolysed and could not be shown to have any lamella structure in electron microscopic preparations.

The present-day biophysical interest in phospholipids naturally centres around the struetural arrangement of such molecules in various solvents - and in particular in water. The accepted interpretation of the results obtained by $\mathrm{X}$-ray diffraction, light scattering and with polarized light, is that most phospholipid mixtures consist of concentric layers of bimolecular leaflets intercalated with water. The smallest repeating unit of mixed phospholipids in the presence of protein has recently been examined and the precise significance of the electron opaque lines of methacrylate embedded, osmium-fixed material discussed by Stoekenius, Schulman and Prince ${ }^{5}$. Their evidence, together with that of Finean", strongly suggests that the smallest unit membrane recognizable in model lipid membranes is a bimolecular leaflet covered on both sides with protein-a structure postulated by Danielli nearly thirty years ago and recently presented by Robertson? as a structural entity in some biological cell components.

Of particular interest to the biologist is the intermolecular arrangement of the phospholipids and sterols in the plane of any unit membrane or film. Dr. D. G. Dervichian and de Bernard ${ }^{8}$ have already shown that in monolayer studies, lecithin forms molecular condensations with cholesterol, and Willmer ${ }^{2}$ has recently indicated how such mixtures might give rise to a variety of mosaic patterns, conceivably controlling the permeability of membranes or in facilitating the absorption of specific proteins (for example, gonadotrophin).

The precise orientation of the ionic groups of the phospholipid is at present a matter of some controversy, but the concensus of opinion is that with pure phospholipids the charged groups lie in a nearly level plane at the water interface. Finean ${ }^{10}$, however, has presented evidence that cholesterol might realign the base of a phospholipid away from the water; in so doing, local areas of phospholipid surfaces might present net negative $\zeta$ potentials.

As it is now possible to prepare large quantities of chemically pure, although inhomogeneous in fatty acid, lecithin, this substance has been studied extensively in terms of its conductivity, viscosity and micelle formation. Drs. P. H. Elworthy and D. S. McIntosh, examining the light scattering of lecithin, found that the micellar weights increased as the polarity of the solvent decreased. They also concluded that in their series of solvents - ethanol, $n$-butanol and $n$-hexanol-the polar groups were probably hidden, while the hydrocarbon chains protruded outwards into the solvent. This result is of great interest when it is remembered that lecithin exists as very large micelles in water and with the polar groups outwards.

The behaviour of fairly concentrated sols of lecithins in water with salt solutions has formed the basis of a study by Dr. L. Saunders and was reported to the meeting. He finds that a film of some measurable? mechanical strength forms at the sol/salt interface and that this film has some of the permeability characteristics of cell membranes. Presumably the intermicellar channels restrict the diffusion of divalent and, to a lesser extent, monovalent ions.

Finally, it must be remembered that phospholipids and sulpholipids are integral parts of living cells and as such are in dynamic equilibrium with metabolic: and structural processes. Isotope incorporation studies have repeatedly shown that certain phosphatides can exhibit high rates of turnover in cells undertaking active secretive or ingestive functions ${ }^{11}$. L. E. Hokin and M. R. Hokin, for example, reported how the salt gland of certain marine birds rapidly incorporated phosphorus-32 when the gland was stimulated with acetyl choline-the normal physiological stimulus. Their evidence is suggestive that in this instance sodium transport is coupled to the renewal of phosphate in phosphatidic acid, a process which appears to be catalysed by the eyclic action of 
diglyceride kinase and phosphatidic acid phosphatase. The questions raised during the course of this meeting suggest that it would be foolish to expect a complete understanding of the function of phospholipids even within the next thirty years. A. D. BANGHAM

${ }^{1}$ Maclean, H.. and Maclean, I. S., Lecithin and Allied Substances, second edition (Longmans, Green and Co., London, 1927). 'Folch, J., Lees, M., and Sloane-Stanley, G. H., J. Biol. Chem., 226,
497 (1957).

${ }^{3}$ Dawson, R. M. C., Biochem. J., '75, 45 (1960). ${ }^{4}$ Lea, C. H., Rhodes, D. N., and Stoll, R. D., Biochem. J., 60, 353
(1955).

Stoeckenius, W., Schulman, J. H., and Prince, L. M., Kolloidzschr., $169,170(1960)$

- Finean, J. B., J. Biophys. Biochem. Cytol., 6, 123 (1959).

'Robertson, J. D., Biochem. Soc. Symposia, 16, 3 (1959).

- Dervichian, D. G., in Surface Phenomena in Chemistry and Biology, 70 (Pergamon Press, London, 1958).

'Willmer, E. N., Biological Reviens, 36, 368 (1961).

${ }^{10}$ Finean, J. B., Experientia, 9, 17 (1953).

${ }^{11}$ Sbarra, A. J., and Karnovsky, M. L., J. Biol. Chem., 235, 2224 (1960).

\section{BUILDING RESEARCH}

$\mathrm{T}$ HE annual report for 1960 of the Building Research Board of the Department of Scientific and Industrial Research (Pp. 99. H.M.S.O., London. $7 s .0 d$.) is written and illustrated with the clarity which has characterized previous reports, and provides a convenient summary of the very diverse activities of the Building Research Station.

Before a new building material can be used with confidence, information is needed on many aspects of its behaviour over long periods of time, and the devising of suitable accelerated tests is a major problem in this field of research. The present report describes such a test for the weathering of polyester roofing sheets reinforced with glass fibre. Work is in progress on the behaviour of rain-water goods made from various plastics; the chief problem here appears to be lack of colour stability.

Another group of materials, lightweight aggregates for structural concrete, poses many problems including mix design, bond strength, moisture movement, and corrosion of reinforcement.

Work in this field, begun in 1957, is still in progress, and aims to provide the basis for a future code of practice.

Like most similar organizations, the Building Research Station is often asked to solve a problem within a fow months. Their experience has shown that "superficial short-term examination of problems is apt not to be rewarding". Unhappily, the converse is not always true, and one feels sympathy for the workers on stone preservatives who report, after five years investigation, that "no 'stone preservative' treatment has yet served its purpose well enough to merit commendation. Some have done more harm than good ... nothing of proven value has emerged ...".

Another important group of investigations is concerned with the economics of building construction and maintenance. A survey of 1,000 post-war houses in Scotland has shown that certain non-traditional forms of construction lead to abnormally high maintenance costs, especially in conditions of severe exposure. Prefabricated systems have a tendency to leave small quantities of work to be completed by traditional methods, at disproportionately high cost.

The structural designer will be interested in the development of realistic design methods based on more comprehensive data than those now available. New surveys of actual floor loads and snow loads on buildings are now in hand, and the problems of wind loading on tall buildings are also receiving attention.

An important study of composite action in build. ings is in progress. Attention to the interaction of beams and slabs, and of walls and structural frames can make more difference to frame design than can the most elaborate frame analysis.

The Building Research Station pioneered soil mechanies research in Great Britain, and is continuing the investigation of pile foundations. It would appear from results quoted in this report that the ability of deep cylinder foundations to carry load by both shaft friction and base reaction is still in some doubt.

This important conclusion appears to be based on a limited series of tests on a laboratory model, and it would be a great help to readers if statements of this nature were accompanied by references to the list of publications at the end of the report. At present it is not at all easy to relate the conclusions reported to the publications giving details of the original work.

The contents of the present annual report cover a very wide field, and this arbitrary selection of topies can do little more than indicate the diversity of matters treated. No mention has been made, for example, of the interesting work on the equatorial comfort index for tropical buildings, or the effect of various construction methods on the earth pressures on buried service pipes. In both cases an attempt is being made to replace the present trial-and-error approach by a logical theory developed from observed facts.

This report should be of interest to all who design buildings or organize their construction.

R. Paul Johnson

\section{INDUSTRIAL RESEARCH AND DEVELOPMENT IN THE UNITED STATES}

O obtain information about the economic
resources allocated to research and development
activities, the National Science Foundation of
America has been conducting comprehensive surveys
of research and development in the economy on a
periodic basis. Such surveys yield economic data
that assist the National Science Foundation, the
Federal Government, and other public and private
organizations to assess the present research and development efforts and to formulate science programmes for the future.

A report* summarizes the results of the 1958 survey of industrial research and development, the survey representing a continuation of the Founda-

* National Science Foundation, Washington. Surveys of Science Resources Series, NSF 61-32: Funds for Research and Developmen Printing Office, 1961.) 65 cents. 